Volume Title: CREATING CONDITIONS FOR ASIAN AMERICANS TO THRIVE IN HIGHER EDUCATION Samuel D. Museus, Marie P. Ting

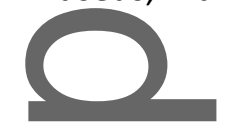

\title{
Editors' Notes
}

Throughout history, racial exclusion has been a hallmark of the Asian American experience (Takaki, 1998). For example, in the late 1800 s and early 1900 s, widespread xenophobia led to Asian immigrants becoming the first groups to be legally banned from entering the United States. And, in the mid-twentieth century, law-abiding Asian American citizens were removed from mainstream society and incarcerated because of their ancestral ties to an Asian nation and the government's lack of trust in them.

Even when Asian Americans have been allowed to participate in mainstream society, racial forces have worked to ensure that they are not fully accepted and engaged in it. One salient example of such forces is the fact that the growing influence of Chinese immigrants in the 1860s leading to the Chinese Massacre of 1871, during which local Chinese American businesses were looted and ransacked while 19 Chinese American men and boys-many who were innocent-were lynched in Los Angeles, California (Dorland, 1894). And, the absence of this example from mainstream U.S. history books reflects another form of exclusion that characterizes the Asian American experience - the exclusion of this community from our nation's mainstream historical narratives. Many other examples of ways that racial forces limit the freedom and influence of Asian Americans abound, including the many ways in which the roles of this population have been limited to those that fit longstanding racial tropes that depict them as excelling in technical math and science skills, but incapable of leadership and advocacy (see Chapter 7).

While racial processes continue to exclude Asian Americans from several sectors of U.S. society, demographic growth and political evolution is challenging this exclusion in unparalleled ways. With regard to demographics, Asian Americans are one of the fastest growing racial groups in the nation (Museus, 2014), and it is estimated that approximately one out of every ten of the nation's residents will be of Asian descent by 2050 (U.S. Census Bureau, 2004). This rapid growth has been accompanied by increased visibility in many areas of society, including the rise of prominent Asian American professional athletes (such as Jeremy Lin in the NBA and Tiger Woods PGA), increased presence and more diverse representations of Asian Americans in the media, the first long-lasting television sitcom about an Asian American family ("Fresh Off the Boat"), the first Hollywood hit centering Asian American experiences in decades ("Crazy Rich Asians"), and the election of a rising number of Asian Americans in U.S. politics.

Accompanying the increased visibility of Asian Americans are indicators of the apparently
growing social and political influence of these communities. In the last few months alone, major mainstream national media outlets have produced stories on the growing influence of Vietnamese

This is the author manuscript accepted for publication and has undergone full peer review but has not been through the copyediting, typesetting, pagination and proofreading process, which may lead to differences between this version and the Version of Record. Please cite this article as doi: 10.1002/he.20319.

This article is protected by copyright. All rights reserved. 
Americans in the U.S. political arena, how Chinese Americans are mobilizing to acquire seats in political office, and the wave of Asian American politicians that are being elected in geographic regions on the West and East Coasts (e.g., Constante, 2018; Hobson, Bentley, Raphelson, 2018). These are all signs that Asian Americans can and likely will play an increasingly influential role in shaping U.S. politics and society moving forward.

The increased visibility of Asian Americans and the production of this edited volume transpire in a politically and socially turbulent time across U.S. society and around the globe. Over the last decade, large-scale tensions have erupted around the most pressing problems plaguing the United States and the world. During this period, national and international social movements to address global warming, widespread poverty, nationalistic xenophobia, and systemic racism and sexism have expanded their reach and influence. And, Asian Americans have been involved in both the mobilization of these movements and resistance to them.

Higher education serves as a critical site for grappling with the aforementioned political and social problems. On one hand, it is part of a larger social system that perpetuates and exacerbates these challenges. On the other hand, institutions of higher education can serve as engines of progress, providing space and resources for their community members to develop solutions to these problems. Given these realities, it is not surprising that higher education is a site of significant political and social conflict. For example, the \#Occupy, \#BlackLivesMatter, and \#MeToo movements have sparked campus protests across the nation and mounting pressures for colleges and universities to take diversity and equity more seriously. And, in the policy arena, increasingly heated debates are taking place about affirmative action and data disaggregation-two issues that heavily shape our system of higher education. Regardless of whether higher education continues to ignore Asian Americans, all indicators suggest that these communities are shaping these major debates and their influence will likely continue to grow.

In response to these realities, this volume offers a call to action, fueled by the recognition that it is imperative that higher education engage Asian American communities in effectively addressing existing political and social problems. In previous work, we and our colleagues have thoroughly underscored the many ways in which racial processes lead higher education to ignore and exclude Asian Americans (for thorough review, see Museus, antonio, \& Kiang, 2016). Many chapters in this volume touch on the ways in which this exclusion continues to permeate higher education systems as well. Such exclusion prevents Asian Americans from developing complex understandings of the relationship between larger social processes and their communities, hinders other communities to develop more accurate knowledge of the Asian American experience, and limits the development of empathy, understanding, and collective action across social groups that is necessary to address ongoing and pervasive social problems.

Perhaps the current debate around affirmative action best illuminates the dangers that result from failing to engage Asian American communities in such major conversations. As the chapters in this volume suggest, dominant narratives are filled with misconceptions about the experiences of Asian American students in the United States and what it means to be Asian American. As the authors of Chapter 1 discuss, anti-affirmative action advocates have exploited these misunderstandings to strengthen their efforts to dismantle affirmative action policies and practices. Despite the reality that affirmative action has benefited Asian American communities immensely, anti-affirmative action advocates continue to utilize one-sided narratives that Asian Americans are victims of these policies to challenge them. This is just one example that highlights

This article is protected by copyright. All rights reserved. 
the urgency of better understanding Asian American experiences and ways that such knowledge can help accurately inform political conflicts and policy conversations.

It could be argued that there are many ways in which engaging Asian Americans can positively shape progress within higher education. For example, deeper analyses of Asian American activism and Asian Americans' roles in hot-button debates around issues such as affirmative action might increase understanding of the complexities of relationships they have with other racial communities and better equip institutions of higher education in fostering productive collaborations that advance racial equity (Chapter 2). More thorough analyses of Southeast Asian American refugee experiences in higher education might inform policies and practices to effectively support and serve newly arriving refugee communities (Chapter 3). Unpacking the experiences of Asian American veterans might help cultivate more complex narratives about how those from oppressed and marginalized communities play key roles in protecting our democracy and the responsibilities of higher education institutions to serve them (Chapter 4). Expanding the discourse around Asian American and Native American Pacific Islander Serving Institutions (AANAPISIs) can further mobilize campus communities that have the capacity to better serve this population (Chapters 4-6). And, exposing the barriers to Asian Americans' access to leadership can help build bridges across communities to advance social justice by deconstructing dominant racial narratives that function to exclude Asian Americans while simultaneously reinforcing other racial communities (Chapter 7). The diverse cadre of authors in this volume provide valuable insights, recent findings from scholarly research, and useful practical implications to advance these conversations.

We hope that this volume will constitute a critical resource for many scholars and administrators who wish to better understand, more effectively work with, and enhance their capacity to serve Asian American faculty, staff, and college students. Equally important, however, is our hope that these contributions underscore the urgency of engaging Asian Americans in larger conversations about college access and success, diversity and equity, democracy, and social justice in higher education. As the Asian American population continues to grow, failing to meaningfully engage them in these broader discussions will likely be increasingly harmful. However, intentionally engaging them in these larger discourses will ensure that we have a more informed citizenry, more complex understandings across identity groups, and a stronger base to advocate for equity in higher education and broader society.

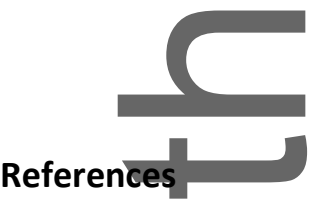

Constante, A. (2018). In California, Asian Americans find growing political power. NBC News. Retrieved from https://www.nbcnews.com/news/asian-america/california-asianamericans-find-growing-political-power-n866611.

Dorland, C. P. (1894). Chinese massacre at Los Angeles in 1871. Annual Publication of the Historical Society of Southern California, Los Angeles, 3(2), 22-26.

This article is protected by copyright. All rights reserved. 
Hobson, J., Bentley, C, Raphelson, S. (2018). California democrats hope Asian-American voters can help flip red districts. National Public Radio (NPR). Retrieved from https://www.npr.org/2018/10/12/656393080/california-democrats-hope-asianamerican-voter american-voters-can-help-flip-red-districts.

Museus, S.D. (2014). Asian American students in higher education. Routledge.

Museus, S.D., antonio, a. I., Kiang, P. N. (2016). The State of Scholarship on Asian Americans and Pacific Islanders in Education: Anti-Essentialism, Inequality, Context, and Relevance. In S. D. Museus, D. Ching, \& A. Agbayani (Eds.), Focusing on the underserved immigrant, refugee, and indigenous Asian American and Pacific Islanders in higher education (pp. 1-54). Charlotte, NC: Information Age Publishing.

Takaki, R. T. (1989). Strangers from a different shore: A history of Asian Americans. Boston: Little, Brown and Company.

Samuel D. Museus is professor in the Department of Education Studies at University of California, San Diego.

Marie P. Ting is associate director at the National Center for Institutional Diversity at the University of Michigan, Ann Arbor.

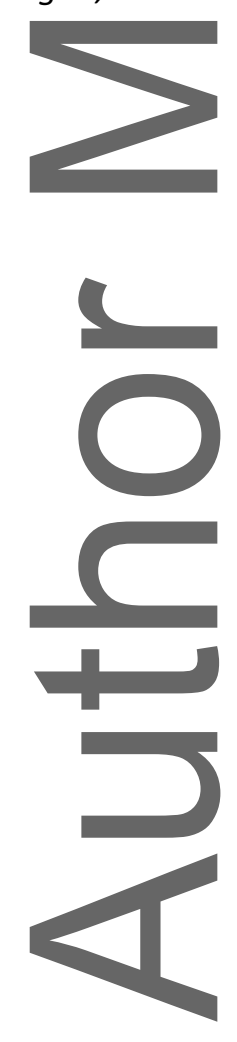

This article is protected by copyright. All rights reserved. 